\title{
Frequency and Extent of Defoliation of Her- baceous Plants by Sheep in a Foothill Range Community in Northern Utah
}

\author{
KEN C. HODGKINSON
}

\begin{abstract}
Defoliation of individual plants by sheep grazing a shrub-steppe community in the foothill ranges of northern Utah was examined during a spring grazing. Five sites (each approx. $120 \mathrm{~m}^{2}$ ) within the paddock were monitored, and populations of one or more species (Aster chilensis, Wyethia amplexicaulis, Lupinus sericeus, Poa secunda, and Koeleria cristata) within these sites were examined daily for defoliation over a 25-day period. Grazing started at different times at each site, but once grazing started each site was visited daily. The proportion of the population of $A$. chilensis shoots that were grazed each day varied but was highest (about $30 \%$ ) several days after grazing commenced at each site. Extent of defoliation of highly palatable species did not differ over time but did increase for $W$. amplexicaulis (forb of low palatability) at the end of the grazing period.
\end{abstract}

There have been many studies in which the diet of animals has been estimated either by direct observation of feeding animals or examination of the ingesta or faeces, and these have provided much valuable information about what plant species animals selectively eat in relation to the species available. However, there is inadequate quantitative information on the influence of grazing on individual plants that comprise the plant community. Recently, Klemmedson et al. (1978) in reviewing research needs on western rangelands of the United States concluded that the highest priority is the study of the dynamics of individual plants and plant communities in relation to grazing and other stresses.

Information on the frequency and extent of defoliation is required to help explain how composition and productivity of particular plant communities are altered by grazing or browsing. Plant physiologists have shown that shoot removal by clipping, at different frequencies and extents, influences vigour and survival of range plants. Implicit in these experiments is that clipping reasonably simulates grazing. However, data on the way free-ranging animals defoliate plants are insufficient to know whether or not clipping satisfactorily simulates grazing.

Grazing pressure on plants in rangelands is usually estimated by measuring the percentage of plants that have been

\footnotetext{
This study was conducted while the author was visiting associate professor, Range Science Department, College of Natural Resources, Utah State University, Logan 84322. during 1975. The author was on leave from CSIRO Division of Land Resources Management, Riverina Laboratory, Private Bag, P.O., Deniliquin. N.S.W. 2710. Australia.

The author gratefully acknowledges the support of Drs. Martyn Caldwell, Fred Gifford, John Malechek, Ben Norton, and John Workman of the Range Science Department, who very generously made available equipment and transport, during this study. Special thanks are due to Ms. Pat Johnson and Mr. Miles Moretti for their assistance with data collection. The research was partly supported through the US IBP Desert Biome Program (Grant No. BMS74-02671-A04, National Science Foundation).

Manuscript received February 6, 1979.
}

grazed or the amount of foliage removed from plants at the end of a grazing period (e.g. Smith and Owensby 1978). However, these methods fail to identify if plants are regrazed and how frequently. The frequency at which tillers of grasses are grazed by sheep, when grown as dense monocultures adequately supplied with water and nutrients, has been examined by Hodgson (1966), Greenwood and Arnold (1968), Hodgson and Ollerenshaw (1969), and Morris (1969). These have shown that individual tillers are often regrazed and the interval between defoliations (i.e. the frequency) decreases with inceasing stocking density. To my knowledge there are no comparable studies reported for rangeland communities, although studies are currently in progress in Southern Africa (Barnes 1976).

The aim of the study reported in this paper was to define the frequency and extent of defoliation of herbaceous plants by sheep grazing a shrub-steppe community in the foothill ranges of northern Utah. Individual plants and parts of plants were monitored during the grazing period to determine the pattern of defoliation, and the amount of leaf removed was estimated by measuring the LAI.

\section{Study Methods}

\section{Location}

The study was conducted in a 2.4-ha paddock which was part of a larger grazing trial at Hardware Ranch near Logan, Utah, (Jensen et al. 1972). It had been heavily grazed each year in the late May/early June period during the preceding 8 years. The elevation of the paddock was about $1,850 \mathrm{~m}$ above sea level, and it had a southern aspect. Soils of the area were of the Ant Flat and Yeates Hollow series (Doell 1966). Average annual precipitation is 406 $\mathrm{mm}$ and the frost-free period is usually from mid-June to midAugust.

Vegetation on the site and the general area was of the sagebrushgrass type and was representative of the foothill ranges of much of Utah and southern Idaho. The dominant shrub species in the paddock was big sagebrush (Artemesia tridentata ssp.tridentata), but bitterbrush (Purshia tridentata) was abundant. There were limited areas dominated by low sagebrush (Artemesia arbuscula) (Fig. 1). The dominant herbaceous species was Pacific aster (Aster chilensis var. adcendens), and mule ears (Wyethia amplexicaulis) was abundant in some areas. Lupine (Lupinus caudatus) and yarrow (Achillea lanulosa) were common. The most common grasses were sandberg bluegrass (Poa secunda) and junegrass (Koeleria cristata).

\section{Study Sites}

Before sheep entered, the paddock was surveyed to define the distribution of the major shrubs. Five study sites were selected 


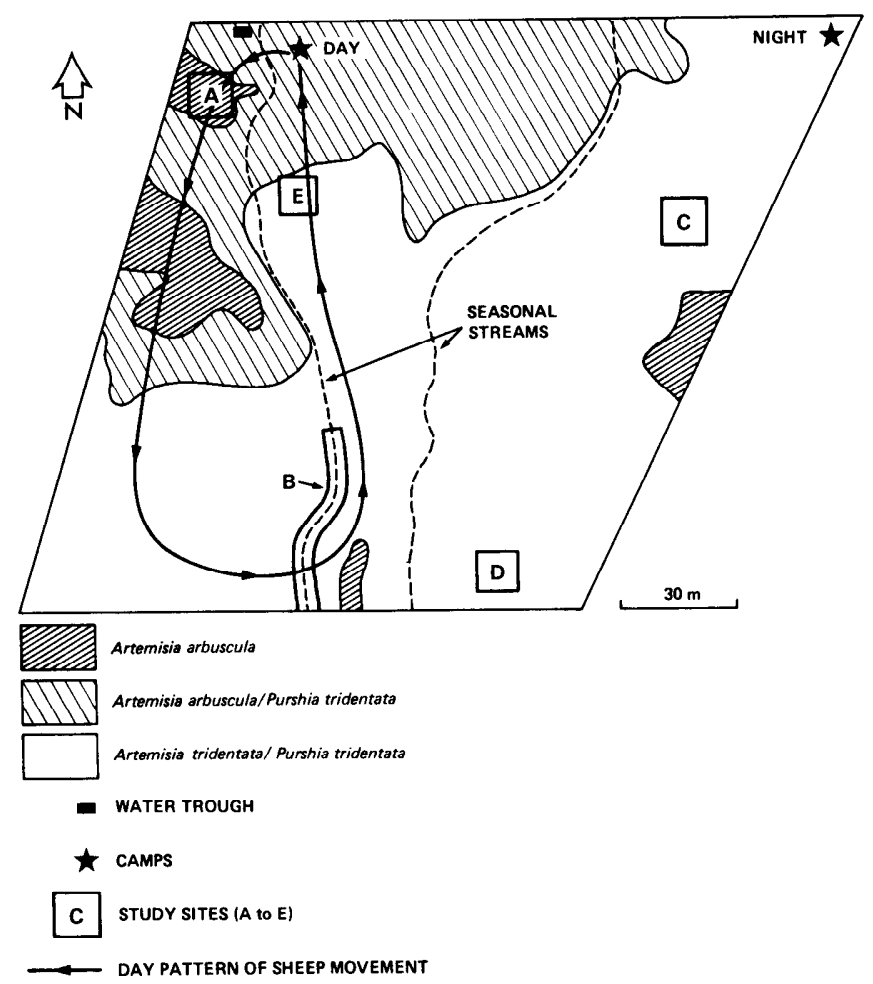

Fig. 1. Layout of paddock showing distribution of vegetation types, study sites, and pattern of sheep movement.

(Fig. 1). Four of the sites (A,C,D,E) measured $11 \times 11 \mathrm{~m}$ and site $B$ which followed the stream bed was $55 \times 2 \mathrm{~m}$ (average) wide.

The canopy cover of the shrub species in each site was determined by line transect. At each site twelve transects $11 \mathrm{~m}$ long were laid out $1 \mathrm{~m}$ apart. From the proportion of the line intercepted by shrubs, the percentage cover was estimated. The density of $W$. amplexicaulis plants was estimated from the numbers of plants within stratified belt transects $0.3 \mathrm{~m}$ wide and $11 \mathrm{~m}$ long.

The structure and composition of the herbaceous layer in sites A,B,C, and D (including $A$. arbuscula in A) were described by estimating the mean leaf area index (LAI) for each species using the inclined point quadrat method (Warren Wilson 1960). A pin angle of $32.5^{\circ}$ was used, as the majority of the species had an erectophile habit (Warren Wilson 1959). There were 12 sets of 24 quadrats for each site and the position of each set was determined by restricted randomization. In sites $C$ and $D$ the set was placed in the open spaces between bushes. The position of each set was marked with nails pushed into the ground and after the grazing period the LAI of each quadrat was remeasured to estimate the percentage of the leaf area removed by grazing.

\section{Grazing Period}

On May 27, 19 sheep ( 12 ewes and 7 lambs) were placed in the paddock, and 6 days later, June 2, another 27 (14 ewes and 13 lambs) were added. All were removed from the paddock on June 21 . Grazing during late May/early June is the recommended season of use for these foothill ranges (Jensen et al. 1972). On the basis of a mature ewe plus lamb equalling 0.2 animal units, the paddock carried 1.24 AUM's per hectare, or provided 190 sheep days per hectare.

\section{Measurements on Individual Plants}

Within each site 50 small pegs were pushed into the ground to form a grid of regularly spaced points about $1 \mathrm{~m}$ apart. The stakes protruded $3 \mathrm{~m}$ above the soil surface, and it is assumed that sheep were neither attracted nor repelled by the presence of the pegs. Before sheep entered the paddock, 50 individual plants of one or more species that were closest to the marker pegs were selected for regular observation in each site. The unit of plant selected differed according to species. For grasses the unit was the tiller, for Aster chilensis a shoot arising from a rhizome, and for $W$. amplexicaulis and $L$. caudatus, the whole plant. Since the plant unit selected was based on its closeness to each peg it is assumed that the plants (or their units) marked, represented a true subsample of the population of each species within each site.

To facilitate re-examination of plant units, a nail (head painted white) was pushed into the soil close to each unit. Shoots of $A$. chilensis were marked in sites A, B,C, and D; $W$. amplexicaulis in sites $\mathrm{A}$ and $\mathrm{B} ;$ L. caudatus in site $\mathrm{E}$; and grass tillers in site $\mathrm{A}$. The grass tillers marked in this site were a mixture of two species, Poa secunda and Koeleria cristata.

Each day during the grazing period these marked plant units were individually examined. Care was taken to ensure that plants were examined only when the sheep were camping or feeding at a distance from a particular site. It was considered that sheep movements were not significantly affected by the daily examination of plants because of the cover offered by the shrubs and the relatively steep terrain.

Plant units were examined to see if they had been grazed during the preceding 24 hours. Examination of plants took place each day between the hours of $0930 \mathrm{~h}$ and $1500 \mathrm{~h}$; 24-hour period beginning and ending at noon. The tips of all leaves of each plant unit were marked by covering a small area with white nail polish. When a leaf was partially or completely grazed, the grazed edge was remarked. By this means assessment of whether or not a plant has been grazed during the preceding 24 hours and the number of leaves grazed could be made from these measurements. The frequency that individual plants were grazed was determined, and from this were derived estimates of the grazing interval (the mean number of days between successive grazings of a plant).

The length of individual leaves that comprised each plant unit was measured at the start and during the grazing period and after each defoliation. For the grasses, $A$. chilensis and $W$. amplexicaulis, a relationship between the total lengths and area of those leaves on a shoot, tiller, or plant was established by measuring the length and area of leaves, taken at random. From the lengths of leaves, the leaf area removed at each grazing was estimated.

Daily observations were made of Purshia tridentata to determine when the sheep started eating this palatable shrub. Other shrubs in the paddock were known to be unpalatable to sheep (Jensen et al. 1972). During the period when the plant measurements were taken, the position and behaviour (resting, feeding, or walking) of the sheep were recorded.

\section{Results}

\section{Site Characteristics}

Site A was dominated by $A$. arbuscula (Fig. 1 and Table 1) and was the first area grazed by sheep as they left the day camp.

Site B was the creek bed, and for the first 10 days water flowed over some of this area and the soil remained moist

Table 1. Some characteristics of the study sites.

\begin{tabular}{lccccc}
\hline & \multicolumn{5}{c}{ Site } \\
\cline { 2 - 6 } & A & B & C & D & E \\
\hline $\begin{array}{l}\text { Cover of shrubs } \\
\text { (\% of ground area) }\end{array}$ & 37 & 0 & 30 & 44 & 37 \\
$\begin{array}{l}\left.\text { Density (plants } / \mathrm{m}^{2}\right) \\
\text { of Wyethia ample- } \\
\text { xicaulis }\end{array}$ & 4.4 & 8.3 & 9.5 & 0 & 0.1 \\
$\begin{array}{l}\text { Number of herbaceous } \\
\text { species present }\end{array}$ & 16 & 19 & 10 & 8 & $\begin{array}{c}\text { Not } \\
\text { measured }\end{array}$
\end{tabular}


for the duration of the grazing period. The amount of herbage and the diversity of species was the highest of all the sites. During the day sheep usually grazed the creek bed on their return to the day camp.

Site $\mathrm{C}$ was typical of much of the paddock and contained a moderate cover of $A$. tridentata and $P$. tridentata. The density of $W$. amplexicaulis was also high on the site. No sheep were ever observed on this site; but since it was grazed, sheep must have visited the site during the late afternoon or early morning while moving to or from the night camp.

Site D was on a steep slope having a heavy cover of $A$. tridentata and $P$. tridentata. It was the furthest site from either camp, and sheep were seen grazing the site only on one occasion.

Site $E$ was similar to $C$ and D except it contained a significant number of $L$. caudatus plants, which were not present in any of the other sites.

\section{Grazing Pressure on Each Site}

Continuous observation of the number of sheep, their feeding activities and duration in each site was not possible, but a relative index of daily grazing pressure was obtained from the proportion of plants grazed each 24-hour period. Although these data are species specific, the grazing pattern for the other palatable plants was probably similar to that of A. chilensis.

The grazing patterns for each site (Fig. 2) suggest that the sheep first utilized areas close to their day camp (sites A and $B$ ) and then grazed areas that were less accessible and with a heavier shrub cover (sites $C$ and D). The grazing pressure at each site fluctuated over time, but there were days when up to $30 \%$ of the shoots of $A$. chilensis were grazed. These higher grazing pressures occurred soon after the sheep commenced grazing a site. Generally, after the sheep commenced grazing a site, it was visited at least once a day.

$W$. amplexicaulis was not eaten until Day 7 in site $\mathrm{A}$ and Day 11 in site B and then only occasionally. During the last 6 days of the grazing period, the proportion of the population
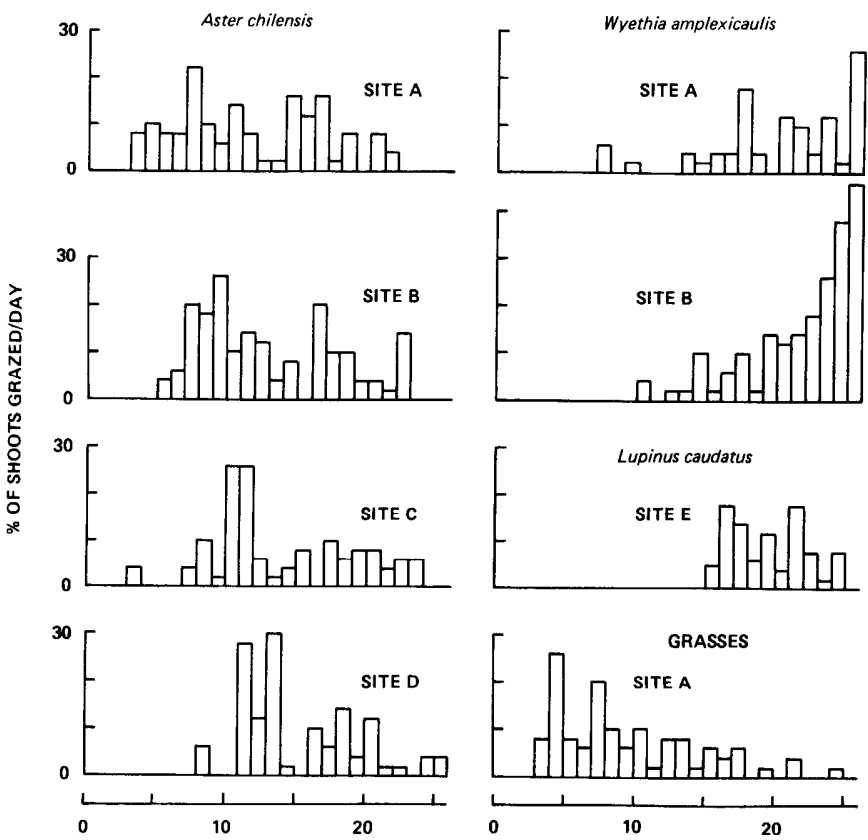

DAYS OF GRAZING

Fig. 2. The percentage of the marked shoots of four species grazed at each site each day. of plants in site B that were grazed steadily increased reaching $46 \%$ on Day 26.

L. caudatus plants in site E were grazed only towards the end of the period and there was no indication that the grazing pressure on these plants changed once grazing of them commenced.

The grass plants on site A were utilized throughout the period with the highest grazing pressure being exerted early in the period and progessively declining as forage availability fell.

Grazing of the $P$. tridentata commenced on about day 15 and steadily intensified over the remaining period of grazing.

\section{Frequency of Grazing Individual Plants}

Overall, plants of the species examined were grazed on average once or twice (Fig. 3) during the 25-day grazing period. Plants of $W$. amplexicaulis were grazed up to eight times on site B and on site A only four times. Shoots of a few $A$. chilensis plants were grazed up to five times.

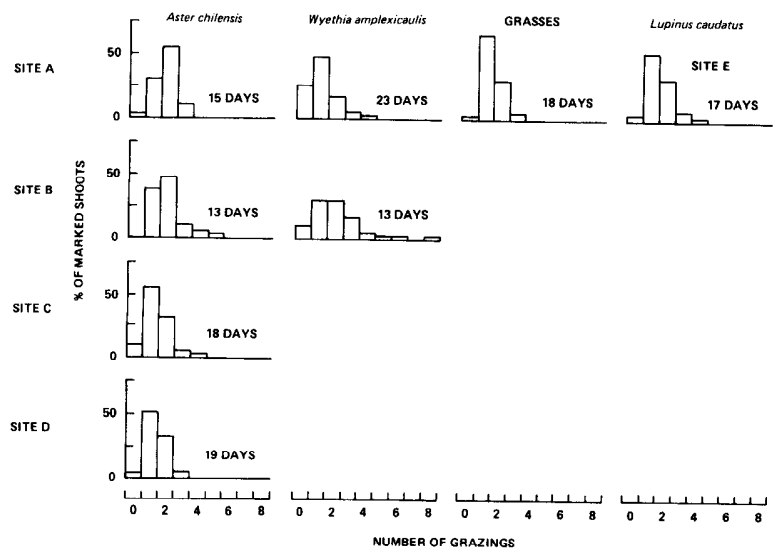

Fig. 3. Frequency distribution of the marked shoots of four species at five sites according to the number of grazings. The mean grazing interval (days) is given for each population of species.

A greater proportion of $A$. chilensis shoots were grazed twice on sites $A$ and $B$ compared with sites $C$ and $D$, an expected outcome considering the greater grazing pressure on the first two sites.

From these grazing frequency distributions, the mean grazing interval for each population of species was estimated and these are included in Figure 3. Grazing intervals ranged from 13 days on site B (for both $A$. chilensis and $W$. amplexicaulis) and 23 days for $W$. amplexicaulis on site $\mathrm{A}$.

\section{Influence of Shrubs on Utilization of Individual Plants}

A relationship between proximity of individual shoots of A. chilensis and grasses to adjacent shrubs and time of first grazing was sought by regression analysis. For no sites was there a statistically significant trend over time indicating that all plants of these species were equally available to grazing sheep. The marked plants included those under as well as between bushes.

The only effect of shrubs on utilization of a plant species was observed in site $C$ where on about Day 18 of the grazing period all $W$. amplexicaulis plants under $P$. tridentata shrub canopies were eaten partly $(17 \%)$ or completely $(83 \%)$ while plants in open spaces were largely ignored (5\% completely eaten, $57 \%$ partially eaten and $38 \%$ not grazed). The reason for the greater acceptability of plants under $P$. tridentata is 
not known but at the time it was thought that the shrubs protected those plants growing under them from the damage of a heavy frost that had occurred several days earlier.

\section{Amount Grazed from Individual Plants}

The mean leaf area of $A$. chilensis shoots was $7 \mathrm{~cm}^{2}$ at the start of the experiment and there were no statistically significant differences between sites in the initial mean leaf a reas of the shoots selected. The mean amount of leaf area removed when shoots were first grazed was $5.3 \mathrm{~cm}^{2}(75 \%$ of the initial leaf area). For the grasses in site A, 67\% of the leaf area of tillers was removed on average when first grazed (or 1.3 $\mathrm{cm}^{2} /$ tiller). There were no statistically significant differences between sites or over time in the amount grazed at any one time from each $A$. chilensis shoot or grass tiller.

In contrast, the $W$. amplexicaulis plants in sites A and B, being less palatable than $A$. chilensis, were infrequently and lightly grazed initially; but as herbage availability decreased towards the end of the grazing period, the mean amount grazed from plants each day steadily increased from 100 to over $300 \mathrm{~cm}^{2} /$ day at site B (Fig. 4). However, at site A the consumption rate of $W$. amplexicaulis did not change over time and averaged $200 \mathrm{~cm}^{2} /$ plant/day.

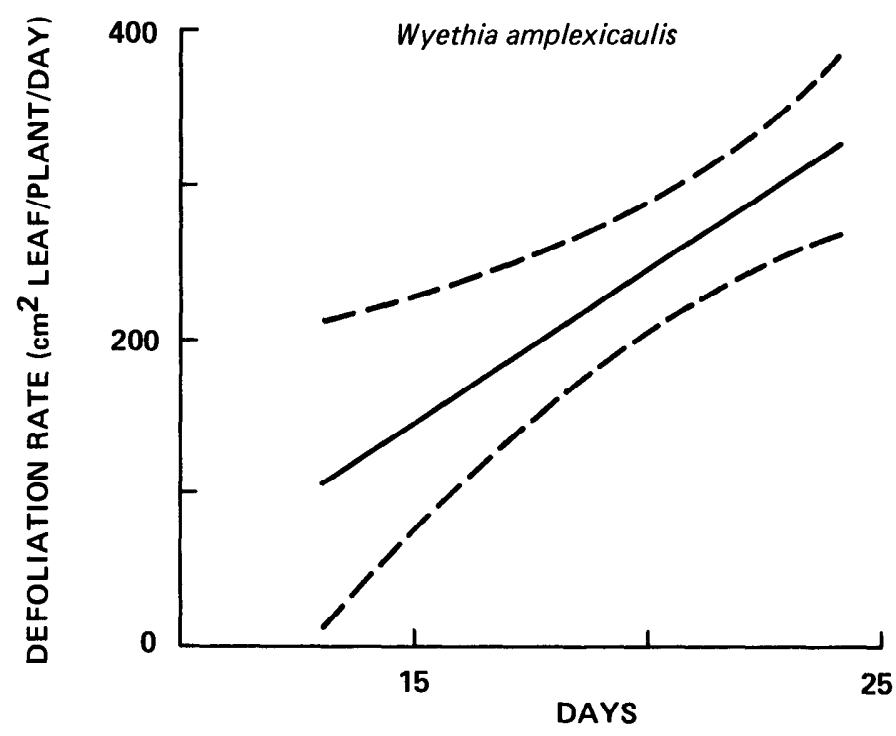

Fig. 4. Relationship between defoliation rate from the start of grazing for Wyethia amplexicaulis plants at site $B$. The line was derived by regression analysis and the dashed curves are the $95 \%$ confidence belts.

The change in the leaf area of the populations of the species during the grazing period is shown in Figure 5. Differences in the rate and direction of change reflect the time when grazing commenced at each site and the subsequent grazing pressure. Note the doubling in the leaf area of the $W$. amplexicaulis plants before the sheep began grazing them.

\section{Amount of Herbage Grazed from Sites}

The measurement of the LAI before and at the end of the grazing period is a conservative estimate of the amount of herbaceous foliage removed from each site by the sheep (Table 2). Overall, the reduction was about $55 \%$. This would be less than the true utilization, as the method did not account for growth of plants before they were grazed or between grazings. Compared with the amounts grazed from the marked plants (Fig. 5), the true utilization was probably $15 \%$ higher, about $70 \%$. There were differences between sites

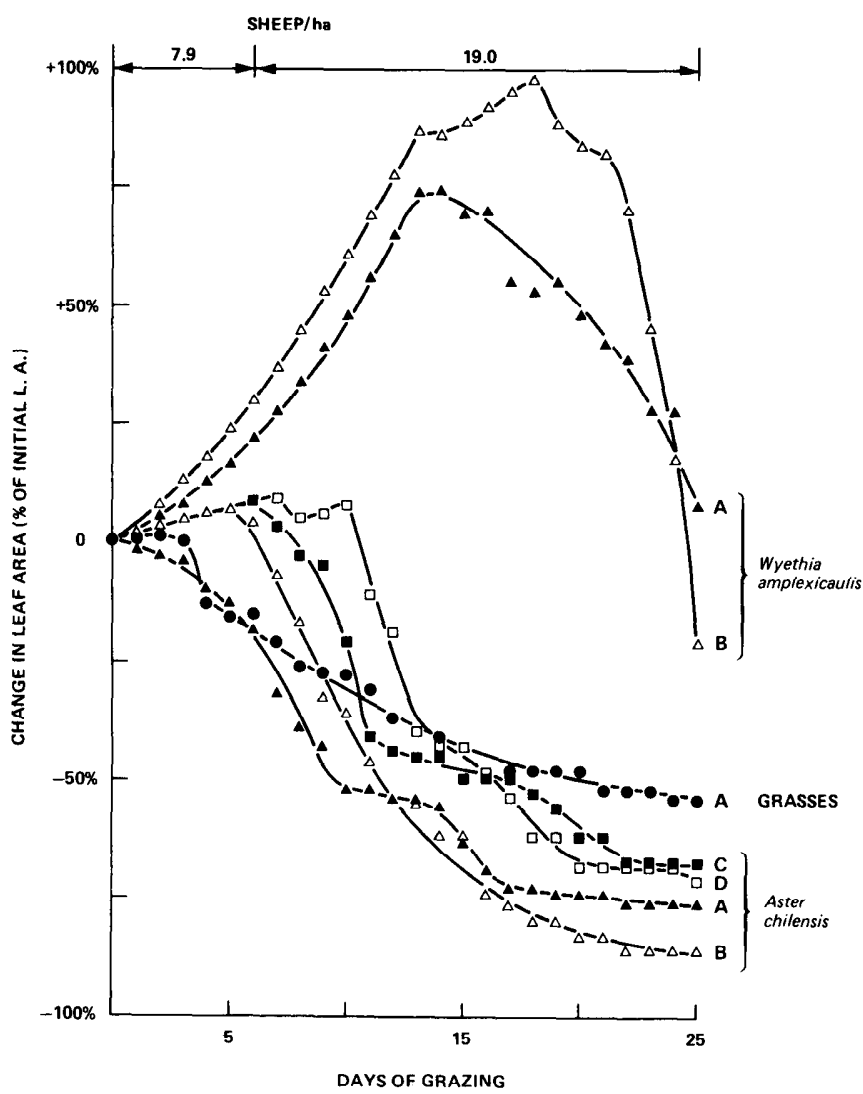

Fig. 5. Proportional changes in the leaf area of three species at four sites during the period of grazing.

in the percent utilization of the forbs and grasses present but this would be expected as the grazing pressure differed among sites.

\section{Discussion}

The method used in this study, although tedious, led to an adequate description of how the most abundant herbaceous species were utilized over time. However, in considering the implications of this study it should be borne in mind that the grazing situation was somewhat artificial in that a small flock of sheep was confined in a small paddock and only some of the plant species forming the sheep's diet were monitored.

The proportion of the shoot population of $A$. chilensis grazed each day fluctuated over time and differed between sites (Fig. 2). The overall pattern was that once grazing started, $25-30 \%$ of the shoot populations was grazed each day for several, usually consecutive, days and then the pro-

Table 2. Leaf Area Indices (LAI) of the herbaceous species before and after grazing and the percentage reduction in LAI of the forbs and grasses.

\begin{tabular}{|c|c|c|c|c|c|}
\hline & \multicolumn{5}{|c|}{ Site } \\
\hline & A & B & $\mathrm{C}$ & $\mathrm{D}$ & Mean \\
\hline \multicolumn{6}{|l|}{ I. Al } \\
\hline Before & 0.55 & 1.33 & 1.43 & 0.89 & 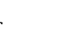 \\
\hline After & 0.22 & 0.75 & 0.52 & 0.37 & \\
\hline \multicolumn{6}{|l|}{$\%$ reduction } \\
\hline Forbs + grasses & 61 & 43 & 64 & 48 & \\
\hline Forbs & 66 & 34 & 68 & 52 & 55 \\
\hline Grasses & 48 & 58 & 50 & 65 & 55 \\
\hline
\end{tabular}


portion declined. The initial high consumption of shoots would be due to an increase in the number of sheep grazing the particular area, an increase in the length of time each sheep spent grazing the area, or a combination of the two factors. The differences between sites in the initiation of grazing can be attributed to distance of sites from the water trough and camps, topography, and possibly differences in shrub cover. Presumably spatial heterogeneity in grazing patterns would increase as paddock size increased (holding stocking density constant) of if stocking density was decreased (holding paddock size constant). The latter situation is well known in practice and has been used as an argument in favour of rotational rather than set stocking grazing systems (e.g. Smith and Owensby 1978).

Another factor, suggested by Iskander (1975) as influencing the grazing pattern of herbaceous plants, is the closeness of plants to shrubs. Iskander postulated that sheep orientate themselves towards conspicuous objects such as shrubs so that plants close to shrubs are grazed before plants in open spaces. When the data from this present experiment were examined for any effect of shrub closeness or utilization there was no evidence that plants close to shrubs were grazed in preference to those at a distance from shrubs. All plants appeared to be equally available for grazing by the sheep.

As forage availability declined during the grazing period there appeared to be no change in the amount removed from shoots or tillers of $A$. chilensis and the grasses, respectively. However, for $A$. chilensis this may be because of the short nature of the shoots and the physical impossibility of the sheep consuming more from each shoot. For the less palatable plant $W$. amplexicaulis, the grazing pressure steadily increased during the final 5 days of the grazing period; that is, the amount of leaf area removed from the plants increased over time (see Figs. 4 and 5). This was more pronounced for the plants in site B than A. However, the increasing utilization of $W$. amplexicaulis can be satisfactorily explained in terms of low availability of other forage rather than resorting to a diet selection theory (Westoby 1974).

The large variation in grazing use of $W$. amplexicaulis plants within the paddock is difficult to explain. It would seem that the differences between habitats in such things as soil moisture content, climate modification due to the presence of shrubs, induce substantial changes in the palatability of the plants. Edaphic and climatic differences may affect palatability by altering the rate of phenological development.

The pattern of grazing described in this study conforms to that described by others for intensively stocked pastures (Hodgson 1966; Greenwood and Arnold 1968; Hodgson and Ollerenshaw 1969; and Morris 1969). The mean grazing intervals for parts of palatable species (13 to 19 days) are within the range reported for these other studies ( 5 to 36 days). Three main reasons for differences between studies in grazing interval are stocking density (doubling the stocking density would halve the grazing interval), tiller or shoot density, and biomass of palatable plants.

Since these foothill ranges are normally seasonally grazed during the spring and early summer for short periods, the pattern of grazing measured in this study would probably be typical. However, in arid rangelands where paddock size is large and stocking rate is low, it would be expected that grazing interval would vary widely in space and time. In rangelands where set stocking is the practice, e.g. Australia, and stocking density is low, between 0.1 and 0.5 sheep/ha, the grazing interval for a given plant could vary from 10 days (low biomass resulting from drought) to 360 days or longer (for a low palatability grass amongst abundant forage).

The pattern of utilization defined for these species has several important implications for future studies on the effect of grazing stress on the population dynamics of individual plant species in communities. First, in multi-specific communities, populations of a plant species should be studied individually especially where the species vary in palatability. Clearly it would be inappropriate to define the grazing pressure on plants in the community in terms of "the actual animal-to-forage ratio at a specific time" (Kothmann 1974). This is illustrated by the fact that had the sheep been removed 5 days earlier, then the grazing pressure on the $A$. chilensis and $W$. amplexicaulis populations would have been high and very low respectively (see Fig. 5), although the overall description for the biomass of herbaceous plants would be that of moderate to high grazing pressure. Second, it would be difficult to simulate by cutting off leaves the pattern of defoliation described in this study. Never was a plant completely defoliated in one day. In view of this difficulty and the need to explain how plant communities change under grazing, it would seem appropriate in future studies to examine the physiological stress in plants that are subject to grazing and growing in natural communities, rather than to simulate grazing by cutting leaves off plants growing in artificial environments. It would also be necessary to define the defoliation pattern using a method similar to the one described in this study.

The long term implications of continued single season use, for herbage productivity from foothill ranges, similar to the area studied, are not known. However, two observations from this study indicate need for caution if single season use is regularly practised. Firstly, it was observed at the end of the summer that there was almost no seed production from herbaceous species in the paddock. In adjacent ungrazed areas there was prolific seed production. Secondly, a significant proportion of the shoots of herbaceous plants was grazed more than once (Fig. 3), indicating a heavy use of the key grasses and herbs. Failure to replenish the soil seed store and reduced plant vigour due to heavy utilization are prerequisites for a decline in range condition.

\section{Literature Cited}

Barnes, D.L. 1976. A review of plant based methods of estimating food consumption, percentage utilization, species preferences and feeding patterns of grazing and browsing animals. Proc. Grassland Soc. South Afr. 11: 65-71.

Doell, D.D. 1966. Effects of summer cattle grazing on big-game winter rang in northern Utah. Unpub. M.S. Thesis. Michigan State Univ. 55 p.

Greenwood, E.A.N., and G.W. Arnold. 1968. The quantity and frequency of removal of herbage from an emerging annual grass sward by sheep in a set-stocked system of grazing. J. Brit. Grassland Soc. 23: 144-148.

Hodgson, J. 1966. The frequency of defoliation of individual tillers in a set stocked sward. J. Brit. Grassland Soc. 21: 258-263.

Hodgson, J., and J.H. Ollerenshaw. 1969. The frequency and severity of defoliation of individual tillers in set-stocked swards. J. Brit. Grassland Soc. 24: 226-234.

Iskander, F.D. 1975. Factors affecting feeding habits of sheep grazing foothill ranges of northern Utah. Ph.D. Thesis, Utah State Univ. 64 p.

Jensen, C.H., A.D. Smith, and G.W. Scotter. 1972. Guidelines for grazing sheep on rangelands used by big game in winter. J. Range Manage. 25: 346-352.

Klemmedson, J.O., R.D. Pieper, D.D. Dwyer, W.F. Mueggler, and M.J. Trlica. 1978. Research needs on western rangelands. J. Range Manage. 31: 4-8. 
Kothmann, M.M. 1974. A Glossary of Terms Used in Range Management Soc. for Range Manage., Denver, Colo.

Morris, R.M. 1969. The pattern of grazing in continuously grazed swards.

J. Brit. Grassland Soc. 24: 65-70.

Smith, E.F., and C.W. Owensby. 1978. Intensive early stocking and season-

long stocking of Kansas Flint Hills Range. J. Range Manage. 31: 14-17.
Warren Wilson, J. 1959. Analysis of the spatial distribution of foliage by two-dimensional point quadrats. New Phyt. 58: 92-99.

Warren Wilson, J. 1960. Inclined point quadrats. New Phyt. 59: 1-8.

Westoby, M. 1974. An analysis of diet selection by large generalist herbivores. Amer. Natur. 198: 290-304. 